\title{
LA VÍA CHILENA AL SOCIALISMO, SALVADOR ALLENDE A 50 AÑOS DE LA UNIDAD POPULAR
}

\section{THE WAY OF CHILE TO SOCIALISM, SALVADOR ALLENDE FROM THE 50 YEARS OF THE POPULAR UNITY}

\author{
Marcos Roitman Rosenmann*
}

\section{RESUMEN}

Se cumplen 50 años del triunfo de la Unidad popular y la vía chilena al socialismo. La figura de Salvador Allende fue su máximo exponente y defensor. El triunfo electoral el 4 de septiembre de 1970 marcó un hito en los procesos de transición. Conceptualizada como vía pacífica, se caracteriza por el respeto a la institucionalidad, el desarrollo de las libertades políticas, la profundización de las libertades sociales, así como el rechazo a la violencia, entendida como la toma insurreccional del poder. La vía chilena se verá frustrada por un golpe de Estado el 11 de septiembre de 1973.

PALABRAS CLAVE: SALVADOR ALLENDE * TRANSICIÓN * SOCIALISMO * GOLPE DE ESTADO * REVOLUCIÓN * COMUNISMO

\section{ABSTRACT}

It is the 50th anniversary of the triumph of the Unidad Popular and the Chilean way to socialism. The figure of Salvador Allende was its maximum exponent and defender. The electoral victory on the $4^{\text {th }}$ of September of 1970 marked a milestone in the processes of transition to socialism. It was conceived as a peaceful way because of its respect for institutions, the development of political freedoms, the deepening of social liberties, and the rejection of violence, understood as the insurrectionary seizure of power. The Chilean path was frustrated by the coup d'etat on September 11, 1973.

KEYWORDS: SALVADOR ALLENDE * TRANSITION * SOCIALISM * PUTSCH * REVOLUTIONS * COMMUNISM 
El martes 11 de septiembre de 1973, dos aviones Hawker Hunter, adquiridos por el gobierno de Eduardo Frei a Gran Bretaña, sobrevuelan Santiago. La orden: bombardear el palacio presidencial. El presidente constitucional Salvador Allende y sus colaboradores más cercanos resisten. En una primera alocución, poco conocida, se dirige al pueblo, eran las 8.45 de la mañana, restaban cuatro horas para que los cohetes SURA-D impactaran sobre La Moneda.

Compañeros que me escuchan: la situación es crítica, hacemos frente a un golpe de Estado en el que participan la mayoría de las fuerzas armadas. (...) No tengo condición de mártir, soy un luchador social que cumple una tarea que el pueblo me ha dado. Pero que lo entiendan aquellos que quieren retrotraer la historia y desconocer la voluntad mayoritaria de Chile; sin tener carne de mártir, no daré un paso atrás. Que lo sepan, que lo oigan, que se les grabe profundamente: dejaré la Moneda cuando cumpla el mandato que el pueblo me diera, defenderé esta revolución chilena y defenderé al Gobierno porque es el mandato que el pueblo me ha entregado. No tengo otra alternativa. Sólo acribillándome a balazos podrán impedir la voluntad que es hacer cumplir el programa del pueblo. Si me asesinan, el pueblo seguirá su ruta, seguirá el camino con la diferencia quizás que las cosas serán mucho más duras, mucho más violentas, porque será una lección objetiva muy clara para las masas de que esta gente no se detiene ante nada (...) Compañeros, permanezcan atentos a las informaciones en sus sitios de trabajo, que el compañero presidente no abandonará a su pueblo ni su sitio de trabajo. Permaneceré aquí en La Moneda inclusive a costa de mi propia vida (Allende, 2008, p. 133).

Los pilotos Mario López Tobar y Ernesto Gonzalez Yarra lanzan su carga. El edificio arde, las llamas se propagan, la destrucción es total. Las imágenes recorrerán el mundo. Sera la forma en que se recordará el golpe de Estado que derrocó el gobierno de la Unidad Popular.

La vía chilena al socialismo, que Allende reivindicaría en el Gran Templo de la Gran Logia de Chile, el 14 de abril de 1970, se verá truncada:

No queremos la violencia. No necesitamos la violencia (...) Son otros los que pueden usar la violencia, porque tienen los medios para usarla. Nosotros soñamos, Venerable Maestro (...) en un gobierno fuerte, pero un gobierno fuerte que no esté afianzado en la fuerza de las armas, sino en la fuerza moral, en la unidad de un pueblo, en la responsabilidad colectiva. En el hecho social que haya aquí un maestro universitario que se sienta junto al compañero campesino o al obrero. En el hecho que el hombre entienda que la mujer no sólo es un motivo de placer o de explotación. Soñamos con una sociedad distinta $y$ queremos luchar por ella... ${ }^{1}$ (Allende, s.f como se citó en Rocha, 2001, p. 47).

Durante tres años, Chile fue sometido a un bloqueo económico sin precedentes. Atentados y sabotajes se sumaban a la huelga de comerciantes, patronal, latifundistas y de trasporte privado. Escasez, mercado negro, acaparamiento de productos alimentarios, el terreno propicio para llamar a un golpe de Estado. Aun así, el gobierno y su presidente, Salvador Allende, no retrocedían en los principios sobre los cuales se había levantado la vía chilena al socialismo. Respeto a la legalidad, desarrollo de la institucionalidad, ampliación de las libertades sociales, ejercicio de las libertades políticas, rechazo a la violencia y socialización de los medios de producción. Si Allende lo había señalado

1 Discurso ante el Gran Templo de la Gran Logia de Chile. Alocución Inédita, que fue rescatada por el periodista Juan Gonzalo Rocha y editada en el año 2000. Vio la luz en el texto de: Rocha, Juan Gonzalo: Allende Masón. Editorial Sudamericana. Stgo-Chile, 2001. El Discurso, improvisado, dura 85 minutos y constituye uno de los más destacados de Salvador Allende. Fue dictado en plena campaña electoral, de allí su valor histórico. 
en múltiples ocasiones, lo volvería a recalcar en el primer informe al Congreso Pleno, el 21 de mayo de 1971. "Sabemos que cambiar el sistema capitalista respetando la legalidad, institucionalidad y libertades políticas, exige adecuar nuestra acción en lo económico, político y social a ciertos límites. Estos son perfectamente conocidos por todos los chilenos" (Allende, s.f como se citó en Martner, 1992, p. 56).

Los partidos de oposición, sabedores de la decisión del gobierno de mantener el proyecto, desplegaron una acción destinada a legitimar un golpe de Estado. Se decantaron por la violencia como mecanismo de acción política. Sin embargo, Allende no dejó de señalar su apego al orden constitucional. No hubo ocasión donde no mostrara su compromiso, durante la campaña subrayó:

Nosotros los marxistas decimos, Venerable Maestro, que todavía es posible que aquí en Chile, dentro de los cauces legales podamos conquistar el Gobierno; pero esto no se reconocerá jamás por los enemigos, esto nunca se reconocerá, pero sí tendrán que reconocerlo los Hermanos que no podrán negar que nuestra voz es la voz responsable de los que no están predicando, sino que haciendo lo que piensan debe hacerse. Pero también es cierto que tenemos que herir intereses $y$ que estos intereses son poderosos, que son demasiado poderosos $y$ por eso se defienden $y$ por eso la mentira $y$ por eso el terror (Rocha, 2001, p. 46).

Y lo ratificó dos años más tarde, el 4 de diciembre de 1972, durante el XXVII período de sesiones de la Asamblea General de Naciones Unidas en Nueva York:

Vengo de Chile, un país pequeño pero donde hoy cualquier ciudadano es libre de expresarse como mejor prefiera, de irrestricta tolerancia cultural, religiosa e ideológica, donde la discriminación racial no tiene cabida. Un país con una clase obrera unida en una sola organización sindical, donde el sufragio universal y secreto es el vehículo de definición de un régimen multipartidista, con un Parlamento de actividad ininterrumpida desde su creación hace 160 años, donde los Tribunales de Justicia son independientes del Ejecutivo, en que desde 1833 sólo una vez se ha cambiado la Carta Constitucional, sin que ésta prácticamente jamás haya dejado de ser aplicada. Un país de cerca de diez millones de habitantes que en una generación ha dado dos Premios Nobel de Literatura: Gabriela Mistral y Pablo Neruda, ambos hijos de modestos trabajadores. Historia, tierra y hombre se funde en un gran sentido nacional. Pero Chile es también un país cuya economía retrasada ha estado sometida, e inclusive enajenada, a empresas capitalistas extranjeras... (Allende, s.f, como se citó en Martner, 1992, p. 626).

¿Cómo se gestó la Unidad Popular? ¿Por qué el golpe de Estado? Hagamos historia. Octubre, primavera de 1969, el país entraba en dinámica electoral. Las presidenciales se celebrarían el 4 de septiembre de 1970. Gobernaba el demócrata-cristiano Eduardo Frei Montalva (1964-1970). Su triunfo se había cimentado en la campaña del miedo y la guerra psicológica. Esta cuña destinada a las mujeres, radiada en las emisoras de onda media $y$ frecuencia modulada, era parte de la campaña:

Locutor: ¿En qué consiste el buen sentido de la mujer chilena? Locutora: En rechazar los peligros que amenazan Chile. ¡No a los sistemas que aplastan la libertad! ¡No a la politiquería que nos lleva al desastre! Para Chile: ¡Un gobierno Independiente! Locutor: mujer, el destino de la Patria esta en tus manos. Locutora: Acción Mujeres de Chile (Power, 2008, p. 293).

En esta misma dirección, la iglesia católica alertaba del peligro del comunismo y el triunfo de Salvador Allende. Una anécdota protagonizada por Laura Gossens, madre de Salvador Allende, narrada tal y como se lo comentó a Oswaldo Puccio, amigo y secretario personal 
del Presidente, es significativa. Mujer de profundas convicciones católicas, de misa y acudir a la iglesia, se presenta al confesionario. El sacerdote, que probablemente no sabía quién era:

... le preguntó por quién iba a votar en las próximas elecciones, a lo cual doña Laura contesto prestamente que por Salvador Allende ¡¿Cómo!? - le inquiere el sacerdote visiblemente alterado-. ¿No sabe usted que se trata de un comunista, de un hombre malo, que va destruir iglesias, a encarcelar a los sacerdotes, a hacer que violen a las monjas, que le va a quitar los niños a las madres para que los eduque el Estado?' Doña Laura le responde con serenidad que nada de eso va a ocurrir si Salvador Allende sale elegido, porque él es un buen hijo y no va hacer cosas malas -Cómo sabe usted que es un buen hijo- le conmina el religioso con extrañeza. Muy sencillo - le contesta doña Laura - Soy su madre (Rocha, 2001, p. 93).

La guerra psicológica, la campaña del miedo y el terror, permeaba la sociedad chilena. Un hándicap con lo cual Allende contaba. El eslogan utilizado por la Democracia Cristiana en 1964 para combatir los movimientos de liberación nacidos a rebufo de la revolución cubana había sido: Revolución en libertad. Sin embargo, el mandato de Eduardo Frei Montalva acumuló represión, reformas inconclusas y extrema violencia. Su sexenio continuó el mismo camino de su predecesor, el derechista Jorge Alessandri (1958-1964). Salvador Allende describe así, la relación existente entre ambos:

La violencia, pero no la violencia de unas cuantas piedras, la violencia ceñu$\mathrm{da}$, característica de un régimen $y$ un sistema, la violencia en el gobierno de Alessandri en Madeco y Mademsa y en Pedro de Valdivia y en José Maria Caro y superando la violencia y los muertos, la violencia en el gobierno de Frei en las calles de Santiago y en Puerto Montt, en Pampa Irigoyen(...) al fracaso del capitalismo típico de Alessandri se sucede implacablemente el fracaso del reformismo demagógico de la Democracia Cristiana y el gobierno de Frei ${ }^{2}$ (Allende, 1970 como se citó en Rocha, 2001, p. 41).

La demanda de una candidatura unitaria de izquierda estaba en el aire. Desde 1952, comunistas y socialistas habían unido fuerzas en torno a Salvador Allende. Ambas organizaciones participaron en la creación del Frente Popular en 1936, he hicieron posible el triunfo de su candidato perteneciente al partido radical en 1938, Pedro Aguirre Cerda. Salvador Allende sería su ministro de Salud Pública. En su ministerio se promulgaron leyes sobre el seguro médico, la vivienda social y el propio Allende redactó el primer informe sobre la situación medico social de Chile.

La coyuntura demandaba frenar el avance del nazi-fascismo y modernizar el país. El Frente Popular gobernó hasta 1952, pero su último presidente, el también radical Gabriel Gonzalez Videla, traicionó la alianza al promulgar en 1948, la ley de defensa de la democracia, ilegalizando al partido comunista y confinando a sus militantes en el campo de concentración de Pisagua, al norte del país. A su cargo, un joven militar: Augusto Pinochet. En 1970, la unidad otorgó el protagonismo a los partidos socialista y comunista. Salvador Allende resalta la distinción: "El año de 1938, luchábamos por ser la izquierda de un régimen y de un sistema. En 1970 no luchamos por ser la izquierda de un régimen capitalista, luchamos por sustituir el régimen capitalista..." (Allende, 1970, como se citó en Rocha, 2001, p. 44).

La izquierda se redefinía. Los no alineados, los tanques en Praga. La guerra de Vietnam y el sudeste asiático. El antiimperialismo, los movimientos de liberación nacional, el bloqueo a Cuba, la guerra de los misiles, la

2 En el libro de Juan Rocha, Allende, Masón. La visión de un profano, se recoge la Alocución en el templo de la Gran Logia de Chile 14 de abril de 1970 y el pronunciado ante la Gran Logia de Colombia, el 28 de agosto de 1971. En él, Allende profundiza su pensamiento y explicita su posición en la política internacional, América Latina y el imperialismo. 
invasión de Marines a República Dominicana, el asesinato del Che $y$ las nuevas dictaduras amparadas en la doctrina de la seguridad nacional. En ese contexto, la izquierda latinoamericana genera un debate sobre estrategia $y$ formas de acceso al poder político. La crítica a la Unión Soviética y la revolución cultural China estaban sobre la mesa. El pensamiento latinoamericano también daba un paso de gigantes. Fueron momentos fértiles. La Teoría de la Dependencia aunó y dio consistencia al pensamiento crítico. El socialismo era una opción para pensar la superación de la dependencia y el subdesarrollo desde una perspectiva anticapitalista. El debate se centró en las formas de acceso el poder: vía insurreccional o vía pacífica. ¿Reforma o Revolución?

La experiencia chilena condensó la realidad latinoamericana. Tras el triunfo de la Unidad Popular, las miradas se dirigieron hacia su proyecto: la vía pacífica de transición al socialismo. Tanto era la convicción de Allende en el triunfo electoral, y su fe en lograr el objetivo de transformar las estructuras capitalistas en Chile, que a principios de los sesenta, en su visita a Cuba, nada más producirse la caída de Batista, en apoyo a la revolución cubana, se entrevista con el Che. De una larga conversación, el Che le regaló uno de los primeros ejemplares salidos de imprenta de su ensayo La guerra de guerrillas, con la siguiente dedicatoria: A Salvador Allende que por otros medios, trata de obtener lo mismo. Afectuosamente. Che. Misma que estampó en una foto que Allende tenía en su despacho.

Soñamos con una sociedad distinta $y$ queremos luchar por ella, aprovechándonos de la experiencia histórica, pero sin ser imitadores y sin ser repetidores de procesos que en otras latitudes tuvieron el contenido de una realidad para su propia realidad. Alguna vez lo dije vulgarmente y lo repito aquí con perdón de ustedes, dije que la revolución cubana se hizo con gusto a azúcar y sabor a ron; la revolución chilena la haremos con gusto a vino tinto y sabor a empanada de horno. Cada pueblo tiene su propia realidad $y$, frente a esa realidad, los dirigentes responsables tienen que desatar las tácticas que hay que seguir (Allende, 1970, como se citó en Rocha, 2000, p. 47).

Así nace la vía chilena. Su peculiaridad, escribe Joan Garcés, fue:

... reunir un síndrome de elementos definitorios, políticos, sociales, económicos, militares, que la convierten en la experiencia más moderna hasta la fecha de revolución anticapitalista, conteniendo los gérmenes de una modalidad de transición al socialismo nunca antes desarrollada hasta un nivel comparable: plena vigencia de la democracia como forma de vida en el seno de los sectores y organizaciones integrantes del bloque social popular, reconocimiento de derechos políticos y civiles iguales a la oposición, respeto del Estado de derecho como norma de regulación de la vida colectiva, rechazo de la guerra civil como vía de resolución de las contradicciones sociales, libre ejercicio de las libertades de organización, conciencia y expresión sin más restricciones que las contempladas en el régimen legal fundamentado en la voluntad nacional manifestada a través del sufragio universal, libre, secreto y con pluralidad de partidos (Garcés, 2013, p. 15).

\section{Y Salvador Allende lo enfatiza:}

De allí la importancia que tiene la Unidad Popular, que reitero, es un instrumento del pueblo de Chile, nacido de su experiencia y su realidad, no es el producto de la cábala de unos cuantos dirigentes que buscan ubicación en función de ventajas personales o de posibilidades electoreras. Es la responsabilidad histórica de los que nos damos cuenta que este país o hace posible dar un paso hacia adelante en el proceso de auténtica democratización, o 
caeremos en una dictadura civil implacable o en un golpe militar ${ }^{3}$ (Allende, 1970, como se citó en Rocha, 2001, p. 43).

Chile era una sociedad politizada. Los partidos de la derecha, liberal, conservador $y$ Acción Nacional, se fusionan en 1965, dando vida al Partido Nacional. Era la nueva derecha, beligerante, construida sobre la movilización de masas y contraria a cualquier gobierno, fuese reformista o de izquierda. En su declaración de principios aparece el rechazo explícito al marxismo "por artificial y limitado a la interpretación materialista de la historia". Víctor García Garzena, su presidente, enlazó la creación del partido a la necesidad de luchar contra el comunismo.

A la gran mayoría de los chilenos le repugna el comunismo. Tienen un ancestro de hombres libres $y$ altivos demasiado fuerte para admitir un estado que disponga de su persona y de sus bienes. [Esta concepción de forjar un partido de masas, suponía en] síntesis una revalorización del campo político que hicieron distintos sectores que se identificaban con la derecha política hacia mediados de los años sesenta se materializó en un partido con la aspiración de convertirse en una alternativa al centro y la izquierda, abandonando las tendencias cooptativas que habían caracterizado a la derecha oligárquica. Esta nueva disposición suponía abrirse a nuevos grupos sociales, modificar el 'estilo' partidario, articular un proyecto alternativo y crear un nuevo aparato partidario de la derecha (Valdivia, 2008, p. 121).

De esta manera, su:

3 Allende no se equivocó, tras mil días de acoso de la derecha, un golpe cívico militar destruía las esperanzas de cambio democrático en Chile, instaurando un régimen de terror y muerte. La peor tiranía conocida en su historia. Alocución en el Templo... (Op.cit, p. 43). ...rechazo más apasionado al marxismo se vincula estrechamente a la administración democratacristiana y su opción por reformas radicales, especialmente lo relativo al derecho de propiedad y los planes de democratización social. La insistencia del gobierno de no aceptar los reclamos y sugerencias de la derecha $y$ las asociaciones gremiales respecto al proyecto de reforma agraria enardeció los ánimos, derivando en una interpretación de los hechos como obra del comunismo (Valdivia, 2008, p. 114).

Esta fue una de las causas por la cual en 1970, la derecha se presentó dividida en dos candidaturas.

Por otro lado, el movimiento sindical, curtido en mil batallas, había forjado su unidad en 1953, bajo la Central Única de Trabajadores (CUT). La izquierda se agrupada mayoritariamente en torno a socialistas y comunistas. En 1965, había surgido el Movimiento de Izquierda Revolucionaria (MIR) partidario de la vía insurreccional, sus principios estaban fuertemente influenciados por el triunfo de la revolución cubana y la teoría foquista del Che. En 1970, tras la denominación de Salvador Allende, decidió no entorpecer la campaña electoral y suspendió todas sus acciones armadas. Durante el gobierno de la Unidad Popular tuvo una posición de apoyo crítico. Por último, la Falange Nacional, escisión del partido conservador en los años 40, se metamorfoseaba en 1957 en la Democracia Cristiana. Su ideario abrevó en el pensamiento de Jose Antonio Primo de Rivera y Ramiro de Maeztu, emulando a la Falange española y su concepción de la democracia orgánica. En su programa se lee: "La iglesia está por encima de los partidos (...) rechazamos el marxismo, concepción materialista $y$ antirracional de la vida, que fomenta la lucha de clases, conduce a la tiranía y ha fracasado en sus experiencias" (Correa et al., 2001, p. 178). Opuestos al divorcio, fueron defensores de la familia tradicional $y$ el rol subordinado de la mujer Su ideario falangista $y$ anticomunista les unió en los hechos con el gremialismo chileno encabezado por Jaime Guzmán, uno de los redactores de la 
constitución pinochetista e instigador del golpe de Estado y al Partido Nacional, sumándose a la estrategia golpista.

Para las elecciones presidenciales, el mapa electoral estaba definido. La nueva derecha presentó al expresidente, el septuagenario Jorge Alessandri; la Democracia Cristiana optó por un candidato de su ala progresista, Radomiro Tomic. ¿Y la izquierda? Cristianos, laicos, marxistas, socialistas, comunistas, socialdemócratas habían confluido. En diciembre de 1969, el programa de la Unidad Popular se hizo público. Lo firmaron seis organizaciones: el partido socialista, el partido comunista, el partido radical, el Movimiento de Acción Popular Unitario (MAPU), Acción Popular Independiente (API) y el Partido Social Demócrata (PSD). Conocido como el programa de las 40 medidas básicas, se destacaron la supresión de los grandes sueldos, unas jubilaciones justas, seguridad social para todos los chilenos, leche para todos los niños, alimentación para los niños en situación de exclusión, vivienda digna, agua y electricidad, reforma agraria real, asistencia médica gratuita en los hospitales, creación de centros de atención primaria y consultorio materno-infantil, disolución de los cuerpos represivos de carabineros, no más impuestos a los alimentos, creación del instituto del arte y la cultura, así como señeramente se denuncian las políticas de ajustes del Fondo Monetario Internacional.

La Unidad Popular tenía proyecto, ahora enfrentaba su último reto: nombrar al candidato. El Partido Radical propuso a un destacado intelectual y profesor universitario: Alberto Baltra; el MAPU, organización escindida de la Democracia Cristiana, a Jacques Chonchol, ex ministro de Frei e impulsor de su reforma agraria; el partido comunista postuló a Pablo Neruda, y API al senador Rafael Tarud. El Partido socialista aún no decidía su candidato. Sumido en un debate interno, hubo dos postulaciones: Salvador Allende y Aniceto Rodriguez, ambos senadores y el segundo, a la sazón, Secretario General del Partido.

Tras la renuncia de Aniceto Rodriguez, Allende lograría 13 de los 27 votos de la ejecutiva, hubo 14 abstenciones. Partidario de una firme alianza con los comunistas, los sectores medios y la construcción de amplias bases de apoyo, no contaba con el beneplácito de un sector importante de su dirección. Consideraban que estaba "gastado" por tres candidaturas fallidas. Muchos argumentaron que su postulación llevaría a la derrota. A pesar de ello, logró imponerse. El 22 de enero de 1970, la Unidad Popular lo nombra su candidato. El 4 de septiembre de 1970, ganará sobre una derecha dividida. Salvador Allende: 1075616 votos; Jorge Alessandri: 1036278 votos, Radomiro Tomic: 824 849 votos. Su triunfo puso en movimiento las fuerzas más reaccionarias en colaboración con el gobierno de los Estados Unidos, para destruir la vía chilena al socialismo. El 11 de septiembre de 1973, tras el bombardeo del Palacio Presidencial y la muerte del presidente, se impuso hasta 1989, un régimen de terror y muerte. El neoliberalismo se abrió paso mediante una de las dictaduras más abyectas de América Latina.

Salvador Allende, fue un objetivo político de la derecha. Las críticas entrelazaban su vida personal con su militancia. Desacreditar, poner en entredicho sus principios, buscar las contradicciones fueron parte de una campaña que duró décadas. El periódico de la oligarquía, principal medio de comunicación de la derecha, El Mercurio, no perdía oportunidad para calumniarlo. La declarada filiación masónica de Allende fue utilizada para descalificarlo y señalar su oscuro ideario conspirativo.

En 1964, durante la campaña presidencial, El Mercurio publicó su foto con el siguiente pie:

Entra a la logia. El senador don Salvador Allende, candidato del FRAP a la Primera Magistratura del País. En una carta dirigida a su director, Allende respondió sin ambages: Todos los míos lo fueron y mi abuelo llegó a ser Serenísimo Gran Maestro de la Orden Masónica, después de haberse desempeñado con singular claridad como senador radical por Atacama. Fundó la primera escuela laica de Chile (...) y cumplió una labor de ejemplar humanitarismo como jefe de los servicios sanitarios del ejército durante la guerra de 1879 . Por sus 
ideas, en esa época lo llamaron "el Rojo Allende". He recibido, pues, como única herencia un nombre limpio y una vocación para servir al pueblo, nacida de la formación masónica de mis antepasados (...) al revés de otros (...), y allá ellos, que se ven beneficiados con el dinero que sus familiares acumularon de cualquier manera (Rocha, 2001 p. 134).

Fue esta formación, la misma que le llevó a renunciar en 1965 a la masonería, tras considerar que su misión había sido traicionada. Así lo expresa en su descargo:

A mi modo de ver la Orden tiene una misión grande y excelsa: sin precisar enunciados que hay que medir con vara actual los principio de libertad, igualdad $y$ fraternidad para que surja una sociedad exenta de alienaciones, eliminando la cesantía, abierta o disfrazada por los salarios insuficientes; para que se evite la enfermedad suprimible; para que exista un sistema de seguridad social funcionalmente correcto $y$ eficaz en su acción; para que se radique el analfabetismo y para que se abra a todos, el acceso a las anchas rutas de la cultura en sus múltiples expresiones $y$ creaciones; para que se reconozca el derecho a la vivienda que llevan en sí todos los seres y para que el esparcimiento se encuentre al alcance de la generalidad, tanto en el orden físico y espiritual y no represente, como hoy acontece, un privilegio económico de los sectores que menos lo requieren por su vida grata cotidiana. (...) Esta posición de nuestra Orden, necesariamente la llevara a luchar con quienes, acéptenlo o no, son índices de postergación generalizada $y$ con quienes disfrutan de las ventajas de un estatus quo insostenible por inhumano $y$ antisocial. Estas mismas batallas se libraron ayer $y$ ahora deberán librarse contra la oligarquía; el feudalismo agrario; la concentración financiera monopólica, el colonialismo; el neocolonialismo y el imperialismo, $y$ el obscurantismo religioso y dogmático. La Orden, si adopta tal actitud consecuente con las responsabilidades de nuestra hora, no podrá guardar silencio $y$ enclaustrarse en sus templos (...) Pero una Orden que nada dice cuando se siembra el terror psicológico masivo sobre la basa de la mentira internacional durante nuestros procesos cívicos, es algo sin vigor espiritual. Una Orden que no reacciona para procurar que no se vulneren la soberanía y la libre determinación, es algo también sin vida. Una Orden que nada dice cuando se masacran e invaden a los pueblos porque una nación se reserva el derecho a determinar, por sí y por su poderío armado, cuál es el sistema político o económico que considera aceptable, es una institución que no vela por la libertad, ni por la igualdad ni por la fraternidad ${ }^{4}$ (Allende, s.f., como se citó en Martner, 1992, pp. 259-260).

Hubo quienes consideraron una contradicción ser marxista y masón. Allende respondía:

Para nosotros es un mito hablar de la justicia, cuando los pueblos famélicos $y$ hambrientos que son potencialmente ricos y que viven como pueblos pobres, empobrecidos por la alianza antipatriótica de las castas oligárquicas y del capital financiero que perforó nuestra economía y que nos demoño políticamente. Para nosotros, digo para nosotros, y planteo que puedo y creo tener el derecho a sostener que no hay ninguna contradicción entre poder decir que un Hermano piensa que el método científico del marxismo le permite apreciar la historia y decir que no ha renegado de los principios masónicos. Si yo creo en la Fraternidad que me

4 Su renuncia fue rechazada declarando al Hermano Allende en condición de durmiente. 
enseñaron en los templos, si yo creo en la igualdad que me enseñaron en los templos, si yo pienso que es cierto que los templos me hablaron de Libertad, yo no me imagino que pueda haber fraternidad en un mundo donde el poderoso aplasta al pequeño desde el punto de vista de la correlación de fuerzas de los países (Rocha, 2000, p. 45).

En esta campaña de desprestigio, $E l$ Mercurio, le hizo propietario de un yate de lujo, mostrando la vida burguesa de un "marxista" que se decía defender al pueblo. La respuesta fue inmediata. Remolcó la barca, un bote a remos, hasta Santiago y lo expuso frente al Senado a la vista para todo aquel que quisiera verlo (Martínez, 2009) Su personalidad y su comportamiento ejemplar, hizo que surgiera el Allendismo. Más allá de la militancia socialista, Allende encarnaba el sentido común del pueblo chileno, de allí su liderazgo. Fue siempre cercano, amigo de sus amigos, crítico $y$ enemigo noble, rechazaba a los aduladores. Sus actos demostraban coherencia, entrega $y$ principios éticos.

La derecha, incluso después del 11 de septiembre, no ha podido emponzoñar su vida. Por votación popular, Salvador Allende ha sido declarado el personaje más destacado de la historia del siglo xx chileno. Como ejemplo sirva el protagonizado en 1967, siendo presidente del Senado. En sesión plenaria, el ministro de Hacienda del gobierno de Eduardo Frei Montalva, el democristiano Andrés Zaldívar, defendía la ley de reajuste salarial. Mientras intervenía, su mujer era trasladada e ingresada de urgencia por un parto prematuro con riesgo de su vida. Allende, a quien le comunicaron la noticia, tomó la palabra y dijo al resto de senadores que el ministro tenía un grave problema familiar y pidió suspender la sesión. Zaldívar, relata que nunca ha podido superar el gesto humano de Allende. Aunque no tuvo escrúpulos para avalar el golpe de Estado en 1973. No fue el único gesto: en diciembre de 1972, ya presidente, volvió a mostrar su señorío en defensa de la dignidad del pueblo de Chile. George Bush, embajador de Nixon, pidió entrevistarse con Allende durante su estancia en Nueva York. Joan Garcés (2013) relata el diálogo:

Allende: "quiero reiterar a su gobierno que el pueblo de Chile desea tener las mejores relaciones dentro del mutuo respeto. No identifico al pueblo de EE.UU. con las acciones de la CIA en los asuntos internos de mi país".

Bush: "Señor presidente, la CIA es también el pueblo de EE.UU.".

Allende, levantándose del sillón: "Señor embajador, le ruego se retire".

Bush sonrojado y confuso balbucea: "señor presidente ¿he dicho algo improcedente?

Allende: "la entrevista ha terminado. Adiós".

Y el día del golpe de Estado, hizo gala de ironía. El general del ejército y promotor del golpe, Ernesto Baeza Michelsen, llamó por teléfono a La Moneda pidiendo su rendición. Oswaldo Puccio, relata la conversación: "le preguntó a Baeza cómo estaba su señora y el general le respondió que bien... A continuación le inquirió sobre su estado de salud, ya que había sufrido un infarto (...) Allende, le aconsejó cuidarse mucho y evitar cualquier inquietud. De alguna manera, el general reunió ánimos para trasmitir el mensaje del jefe de los golpistas. Lo que no se sabe es si los tuvo para trasladarle la respuesta de Allende: "dígale que no sea maricón y que venga a buscarme personalmente".

Fueron tres años de estrangulamiento económico, mercado negro, atentados, movilización de la patronal y conspiraciones. Así lo refleja su testamento político, en su última alocución al pueblo de Chile por las ondas de Radio Magallanes a las 09.05:

Trabajadores de mi patria: quiero agradecerles la lealtad que siempre tuvieron, la confianza que depositaron en un hombre que solo fue interprete de grandes anhelos de justicia, que empeño su palabra de que aceptaría la Constitución y la ley, y así lo hizo. En este momento definitivo, el último en que yo pueda dirigirme a 
ustedes, quiero que aprovechen la lección: el capital foráneo, el imperialismo, unido a la reacción, creó el clima para que las fuerzas armadas rompieran su tradición, la que les enseñara Schneider y reafirmara el comandante Araya, víctimas del mismo sector social que hoy estará en sus casas esperando con mano ajena, reconquistar el poder para seguir defendiendo sus granjerías y sus privilegios.

Quien fuera General en Jefe de las Fuerzas Armadas, Carlos Prats, escribe el mismo 11 de septiembre, mientras el golpe se pone en marcha $y$ se produce el bombardeo:

Oigo, parcialmente la alocución pronunciada con voz serena, que el presidente Allende dirigiera al país. Luego empiezo a escuchar los bandos de la Junta de las fuerzas armadas y carabineros de Chile. Me siento profundamente consternado ante el súbito $y$ fatal derrumbe de tantos valores y principios, presintiendo con horror, cuanta sangre será derramada entre hermanos. La tenaz lucha sostenida para impedir que el ejército se dejara arrastrar a la destrucción de su profesionalismo institucional, había sido estéril. Todas las angustias, las tensiones y sacrificios soportados, así como el orgullo y la dignidad humillados, no fueron holocausto a una causa lograda. Pienso en la terrible responsabilidad que han echado sobre sus hombros mis excamaradas de armas, al tener que doblegar por la fuerza de las armas a un pueblo orgulloso del ejercicio pleno de los derechos humanos $y$ del imperio de la libertad. Medito en los miles de conciudadanos que perderán sus propias vidas o la de sus seres queridos. En los sufrimientos de los que serán encarcelado y vejados. En el dolor de tantas víctimas del odio. En la desesperación de los que perderán su trabajo. En la desolación de los desamparados y perseguidos, y en la tragedia íntima de los que perderán su dignidad. Presiento que mis excamaradas de armas jamás recuperarán en vida la paz de sus espíritus, atenazados por el remordimiento de los actos concupiscentes en que se verán fatalmente envueltos y por la angustia ante la sombra de las venganzas, que les perseguirá constantemente. ¿Quiénes fueron los cerebros que los perturbaron hasta el paroxismo? ¿Desentrañará la historia la madeja diabólica de esta conspiración insensata en Chile cuyos instigadores - como siempre- permanecen en la penumbra? ¿Por qué los demócratas sinceros del gobierno y de la oposición no fueron capaces de divisar el abismo al que se precipitaba el país? (Prats, 1987, p. 512-513).

Pero la historia del gobierno de la up y la dictadura supone entrar en otro terreno. Hoy a 50 años del triunfo de la Unidad Popular, rescatamos el pensamiento de Salvador Allende. $\mathrm{Su}$ ideario es reivindicado por casi toda la izquierda, pero muchos son incapaces de asumir su coherencia y la firmeza de convicciones que le caracterizó. Sus aportes constituyen parte del acervo sobre el cual se construye hoy, la alternativa antiimperialista, socialista $y$ anticapitalista. El proyecto de la Unidad Popular sigue vigente.

\section{REFERENCIAS}

Allende, S. (2008). Presente. Ediciones Sequitur.

Correa, S., Figueroa, C., Jocelyn-Holt, A., Rolle, C. y Vicuña, M. (2001). Documentos del siglo xx chileno. Editorial Sudamericana.

Garcés, J. (2013). Allende y la experiencia chilena. Las armas de la política. Edición corregida. Editorial siglo XXI.

Martínez, J. M. (2009). Salvador Allende. Ediciones Nobel.

Martner, G. (1992). (Recopilador). Primer Mensaje al Congreso Pleno. La vía chilena al socialismo. Salvador 1908-1973: Obras escogidas. Ediciones del Centro de Estudios Políticos latinoamericanos Simón Bolívar. Fundación Presidente Allende.

Power, M. (2008). La mujer de derecha. El poder femenino y la lucha contra 
Salvador Allende 1964-1973. Centro de Investigaciones Diego Barros Arana. Ediciones de la Dirección de Bibliotecas, Archivos y Museos.

Prats, C. (1987). Memorias. Testimonio de un soldado. $3^{\text {a }}$ edición. Editorial Pehuén.

Rocha, J. (2001). Allende Masón. Editorial Sudamericana.
Valdivia, V. (2008). Nacionales y gremialistas. El parto de la nueva derecha política chilena, 1964-1973. Editorial Lom.

Fecha de ingreso: 01/09/2020 Fecha de aprobación: 04/11/2020 
